\title{
Continuous Improvement Proposal Process and Operating Model
}

\author{
Pekka Tervonen $^{1}$ and Harri Haapasalo ${ }^{2}$ \\ ${ }^{1}$ Centre for Environment and Energy, University of Oulu, Oulu, Finland \\ ${ }^{2}$ Department of Industrial Engineering and Management, University of Oulu, Oulu, Finland
}

\begin{abstract}
The objective of this study is to create a harmonised continuous improvement operating model. In this study, the theoretical framework for continuous improvement was established on the basis of topical research in the field. The empirical part of the study, based on the interviews, is a model of the best continuous improvement operating models of the internal and external interview units is formed. As a research result, an improvement proposal model is presented. In the model, the continuous improvement activity and suggestion scheme are combined into a single operating model. The operating model combines the requirements of the continuous improvement activity, which have been indicated in the literature, and the observations on the best functioning continuous improvement operating model made in the empirical section. The cornerstones of a successful continuous improvement model are the swift and equal evaluation of the suggestions, encouraging rewards, recognition and feedback. A supportive organisational culture will make it easier for the continuous improvement model to succeed. The support of the management is crucial for the activities.
\end{abstract}

Keywords: Continuous improvement, operating model, supportive organisational culture.

\section{Introduction}

There are several organisational models for continuous improvement. Rapp \& Eklund (2002) represented operating models such as quality control circles, suggestion schemes and problem-solving activities. In addition, Rad (2006) suggested that quality management contains quality management systems, independent working groups and $5 \mathrm{~S}$ activities. According to Aoki (2008), both the suggestion scheme and quality control circles are operating models, in which employees can put forward their own improvement proposals. The continuous improvement activity contains features of suggestion schemes, quality control circles and independent working groups. The continuous improvement activity covers minor improvement proposals that can be implemented swiftly and through small investments and that both groups and employees can implement themselves. The activity emphasises the participation of the whole personnel in the continuous improvement of their working environment.

The research problem of this study is the harmonisation of methods and models to the continuous improvement activity in the case company. The poor level of the continuous improvement activity or the lack of it can be

Copyright (C) 2012 Pekka Tervonen and Harri Haapasalo. This is an open access article distributed under the Creative Commons Attribution License unported 3.0, which permits unrestricted use, distribution, and reproduction in any medium, provided that original work is properly cited. Contact author: Pekka Tervonen Email: pekka.tervonen@oulu.fi 
considered to be lost opportunities to utilise the valuable know-how which a large number of the employees of the case company possesses. The objective of this study is to solve this problem and, thus, to create a collective framework for continuous improvement activities in all of the units of the case company.

\section{Literature Review}

Why is it worthwhile organising continuous improvement activities? It has been stated in the literature that continuous improvement is a fundamental part of business today. As Singh \& Singh (2009) describe, continuous improvement is one of the core strategies of a company. In addition, their study showed that continuous improvement increased a company's profitability and helped produce high-quality products with fewer resources. An employee knows what works and what does not. Employees might also know how things could be improved, if they were asked. The continuous improvement activity provides employees with a channel through which they can have their voices heard and present their ideas (Jepson, 2010; Coleman, 2007; Larikka et al., 2007; Darragh-Jeromos, 2005; Beddows, 2001).

Innovations open up new opportunities for the company. An innovation can be construed as an opportunity to develop the company's business. Ideas must be implemented and inventions commercialised and exploited in the company's products, production and administration alike (Drejer, 2002). According to Boeddrich (2004), the first step in the innovation process is to create a constant flow of ideas prior to establishing actual development projects. The company's efficiency, competitiveness and ability to constantly create innovations depend, in addition to several other factors, on the participation of the company's employees (Tonnessen, 2005). According to Alves et al. (2007), innovative companies exploit various sources of ideas and encourage their employees to innovate, in order to obtain a constant flow of ideas.
The benefits created by people accumulate in the continuous improvement activity. As Garrison (2009) pointed out, if two heads are better than one, what happens when 900 persons are contributing to development! He emphasised that when 900 employees are involved in contemplating problems and their solutions, the number of improvement proposals significantly increases. At the same time, the recognition and feeling of participation of the employees grows. In addition, Garrison (2009) stated that they noted it is beneficial to use thought and reason in production. Employees used more time on productive and development activities than on wasting time on solving daily problems. The continuous improvement activity created by Ala-Laurinaho is also advantageous in that it regularly compiles all the problems and ideas of the employees, after which they can be openly discussed. Employees highly appreciate the possibility to openly discuss matters related to their work (Ala-Laurinaho, 2003).

An important benefit of the continuous improvement activity is the increase in the commitment of the employees to the company. Employees feel that they have an influence in their own work and working environment. Therefore, they actively think and invent better operating methods (Singh \& Singh, 2009; Crail, 2006, Rapp \& Eklund, 2002). Significant benefits which are achieved from the CI activity also include cost efficiency and the proposals that make work faster and easier (Jepson, 2010). For example, a large number of small ideas, ranging from recycling screws to reducing a walking distance by 20 metres, have saved companies a significant amount of money (Mini, 2004).

Lillrank et al. (2001) emphasise that companies must contemplate the objectives that they want to achieve early on when organising the continuous improvement activity. Thus, the benefits of continuous improvement can be better achieved. These benefits include the development of the employees' skills, minor improvements in operations, better work routines and 
methods of employees for the development and improvement of operations. For this reason, it is important to plan the operating model to efficiently support the goals set already in the early stages of the continuous improvement.

According to the literature, the continuous improvement philosophy, which was created and found to function well in Japan, may not work as efficiently elsewhere. For example, Bateman \& Rich (2003) discovered that organisational culture is the main obstacle for the implementation of continuous improvement. Also, Rapp \& Eklund (2002) agree with the notion according to which the implementation of many suggestion systems and problem solving methods has been proven to be more challenging in Europe than in Japan.

Requirements, which must be fulfilled to enable well-functioning continuous improvement activity, are suggested in the literature. The most important aspect of the activity is that every employee has the possibility to have an impact on their work and make proposals which are also efficiently implemented (Jepson, 2010; Anonymous, 2009; Larikka \& Pohjasmäki, 1995). Jepson (2010) also emphasised that it is important to be able to create an atmosphere which promotes initiative and, above all, underlines that no idea is too small to be voiced. These requirements can be satisfied, when the commitment of the management, the adequacy of resources, the goal-orientedness and the continuity of activities are ensured. With these factors, a company can create an organisational culture where everyone has the possibility and willingness to present their ideas, which in turn are swiftly implemented.

Various sources have underlined how important it is that the management commit themselves to continuous improvement (Pollit, 2010; Salaheldin, 2009; Garrison, 2009; Hogan, 2009; Salaheldin \& Zain 2007, Beddows 2001). Resources granted by the management, monitoring and commitment to the activity are essential for a successful activity. In addition, the goals must be clear to everyone. According to Garrison (2009) and Beddows (2001), commitment can mean additional work to the management and changes to operations, but they must be accepted in order to achieve long-term goals.

Ahmed (2009) argues that higher management must believe in their employees being creative and innovative. The management must also provide them with challenges and allow them to express themselves. Ahmed also identifies the responsibility and importance of middle management in the improvement proposal activity. They must understand the principles of the activity and share this understanding with the employees. Pollit (2010) underlined the importance of the commitment by the management, as the management creates possibilities and space where the continuous improvement activity is practiced. The management have to allocate enough resources, such as time, employees and financial support for the activity to be able to function well. Pollit (2010) and Salaheldin (2009) argue that the commitment and support of the higher management are the most important factors enabling successful continuous improvement.

According to Rapp \& Eklund (2002), the commitment of the middle management refers to the immediate management being active and able to accept proposals. One must avoid decreasing the initiative of employees by rejecting a high number of proposals or by postponing feedback to the person who has made the proposal. In addition, it has been noticed that middle management do not consider the activity to be important; instead, it is considered to be a waste of time and resources. Thus, they do not show enough interest and commitment to the activity. This surely decreases the activeness and willingness of employees to participate in the activity. Therefore, it is of essence that the management would show their interest clearly and openly towards the activity and the ideas presented and, in particular, 
allocate resources for the planning and implementation.

The authorisation of employees and groups is an important part of the CI activity. The rights that the continuous improvement teams require for the implementation must be granted (Larikka et al., 2007). Thus, the organised teams can be self-regulated and may implement improvement proposals without the approval of the higher management (Doolen et al., 2008). Organising and managing continuous improvement is not free of charge. The costs of the maintenance of a well-functioning continuous improvement activity come from the training of leaders, the overtime hours of employees / allocating hours, as well as from the acquisition and preparation of manuals and tools (Anonymous, 2009).

According to a study by Bernett \& Nentl (2010), a lack of resources has resulted in the termination of the continuous improvement activities. The lack of resources, such as people, training, time and money, has made the implementation of proposals impossible, and the best way to suppress the activity is to leave proposals unimplemented. The commitment of the management must be seen in the clear allocation of resources, which enables the swift and efficient implementation of the improvement proposals. According to Rapp \& Eklund (2002), continuous improvement requires time to function. The benefits of minor improvements may only be seen in the long run; consequently, the activity must be constantly invested in and resources must be allocated to the continuous improvement in order to materialise actual results.

The organisation must use sufficient time and resources not only to implement the continuous improvement activity, but also to maintain it. The continuous improvement activity requires continuous monitoring and development to stay efficient and wellfunctioning. Hogan (2009) emphasised that in order for the activity to be continuous, the management have to dedicate themselves to the activity, in such a way that real results and a change in the personnel's behaviour can be achieved. The implementation of the continuous improvement activity, similar to the implementation of any new activity, can raise opposition among the employees. There may be views about the operating model being just a temporary change that will be forgotten over time (Bernett \& Nentl, 2010). When these problems have been overcome, it is important to continue the wellimplemented activity by actively monitoring and coordinating the development in such a way that the achieved activity of the employees is maintained (Garrison, 2009). The continuity of the continuous improvement activity can be ensured by training employees, disseminating information about the activity and using campaigns to increase the suggestion activity of the employees.

According to Rapp \& Eklund (2002), continuous improvement requires the time to function. The benefits of minor improvements may only be seen in the long run; consequently, the activity must be constantly invested in and resources must be allocated to the continuous improvement in order to materialise actual results. The management must be patient and trust that the results will be achieved in time. The continuous improvement activity is efficient and productive if the employees have adopted the activity as part of their daily operations (Rapp \& Eklund, 2002). The activeness of the employees can be improved through training, which teaches employees how to solve more challenging problems and to observe their working environment in new ways. In addition, the interest of the employees towards initiative can be increased and maintained with training. The training must begin immediately when an employee comes to work for the first time. This is how the employee will possess all the necessary information to carry out development activities (Hogan, 2009; Rapp \& Eklund, 2002). 
To enable continuous improvement, the management must create an atmosphere and culture where the employees are ready to develop operations (Hogan, 2009). The activity must also be clearly understood by the employees, which means that the operating models which are utilised, machines and equipment as well as rules are clear to them. It is equally important that the employees are active and interested in working in accordance with the models and instructions (Berger, 1997). In addition to the allocation of a sufficient amount of resources to the activity, the persons who are appointed must be active. Ala-Laurinaho (2003) provides an example of a situation where the continuous improvement activity did not work as well as it could have, because some of the continuous improvement teams only seldom had meetings while some never had. Only a few of the teams were productive in their development work. The persons leading the activity have a great responsibility and their actions are crucial to the operation of the team.

\section{Research Design and Methodology}

A constructive research approach was used in this research (Järvinen and Järvinen, 2004). In this research in the first phase of this research, a theoretical analysis, a theoretical frame of reference, is created for the research problem and for the area of research. In the second phase, a system to be planned and implemented is created based on the theoretical frame of reference. The information gathered from the benchmarking of the internal and external subjects of interview, and the conclusions that have been drawn from it form the actual empirical part of this research. Benchmarking means the measuring of both your own and one or several benchmarking targets' capacity, processes, methods, et cetera, for comparison and for the registration of improvements. The objective is to learn from the benchmarking partner in order to improve and intensify own operations (Andersen et al., 1999).
In this research, the elements of success, the greatest challenges and benefits of a continuous improvement model were first determined based on literature. This helped form a picture of what kind of investments, attitudes and instruments a continuous improvement model requires in order to function successfully. The questions for the interviews were created based on the literature survey. The purpose of the questions was to clarify in as detailed a manner as possible, how the themes that had come up in literature become materialised in practice in the continuous improvement models of the case companies and other companies.

\section{Results and Discussion}

A constructive research approach was used in this research (Järvinen and Järvinen, 2004). The information gathered from the benchmarking of the internal and external subjects of interview and the conclusions that have been drawn from it form the actual empirical part of this research. Benchmarking means the measuring of both your own and one or several benchmarking targets' capacity, processes, methods, et cetera, for comparison and for the registration of improvements. The objective is to learn from the benchmarking partner in order to improve and intensify own operations (Andersen et al., 1999). In a wellfunctioning continuous activity, the supportive measures of the operating model are founded on the commitment of the management, resources, training, goalorientedness, operating system and training. With these factors, a company can create an organisational culture where everyone has the possibility and willingness to present their ideas, which are swiftly implemented in turn. 
According to $\mathrm{BM}$ interviews, the greatest challenges faced by the continuous improvement activity are the commitment of the management and the resources allocated to the activity. These challenges become apparent as problems and slowness to implement improvement proposals are. The personnel have no resources or time to plan the implementation of improvement proposals in addition to their daily work. The handling times become longer and the improvement proposals cannot be swiftly implemented. The management must demand the faster handling of improvement proposals. Thus, handling is considered to be important and it is done immediately. Changing organisational cultures and attitudes is naturally slow and difficult, but there cannot be a change if the management does not in fact demand it and in so far as there is no willingness to change.

As a result of this research, the suggestion scheme and the continuous improvement activities have been fused together into the improvement proposal process, which will become a part of the Operational Excellence development activity. The joining of the improvement proposal process in the Operational Excellence activity is in line with the strategy of the company to commit the employees into continuous improvement. As a part of the Operational Excellence activity, the improvement proposal process will have a strong support of the management, which will make the activity's functionality possible. The duty of the employees is to provide improvement proposals and they need not contemplate on whether their proposal is a suggestion or a continuous improvement. The improvement proposals may include ideas which relate to the employees' own working environment, job satisfaction or occupational safety, or they may include new solutions which may help save money or bring substantial benefit for the company and/or the personnel.

The stages of the improvement proposal activity are providing of improvement proposals, handling and evaluation, feedback, implementation and rewarding. The entire process of an improvement proposal activity is presented in figure 1. All improvement proposals are saved in an electronic system at the units. The system functions as a shared data bank of the Group, and enables the distribution of good improvement proposals and the copying of good operating models to every unit of the case company in accordance with the company strategy. The electronic system makes the improvement proposal activity easy to monitor. With the help of the system, the compilation of statistics and the reporting of the activities are simple.

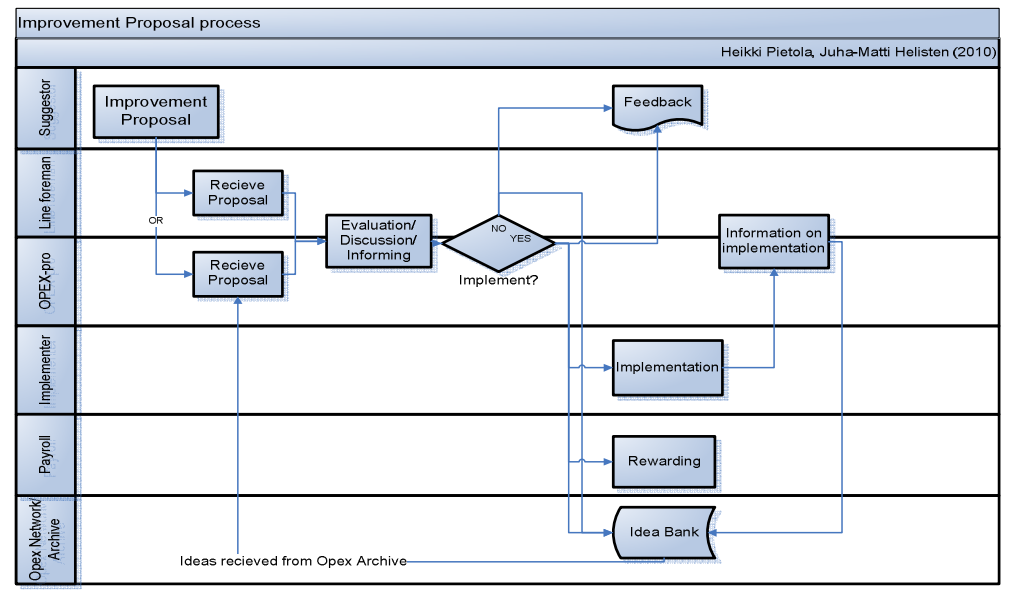

Fig 1. Towards an Operating Model for Continuous Improvement 


\section{Conclusions}

This research shows, based on both literature and empirical observations, that the searching for great innovations only, and especially the lack of management commitment, will significantly weaken the overall results that will be achieved. One important and very essential conclusion of this research was to integrate the suggestion scheme activities and the continuous improvement activity as separate methods into one entity in the case company. This research is significant for the case company as with the help of this research, the ways with which the company ought to collect, evaluate and implement suggestions which its personnel have made to improve its business activities, have been defined. The results of this research can even be exploited generically.

Another factor supporting the use of the continuous operating model is the empowerment of the personnel in decision making. According to literature, the organisations ought to follow through an official empowerment programme in order to succeed in this. With the help of an official programme, improved results can be achieved than with flexible and unofficial programmes. A study ought to be conducted on what an empowering programme includes and how it ought to be followed through, considering the endorsement of the improvement proposal process. Empowerment requires diverse training, for example, on the implementation and maintenance of the improvement proposal process.

While planning the operating model, such ways of action that are essential for the solution have been observed, so that the model could be used as successfully and smoothly as possible alongside the company's other activities. Since the proposed operating model builds very heavily on the use of the right kind of an electronic system as a tool that supports and directs the activities, it would be fruitful to carry out further research on this subject. In the further study, the following questions should be contemplated on the qualities that the system ought to include; what and how the system would need to be able to do; and how the system could be utilised throughout the entire organisation.

\section{References}

Ahmed, A. M. M. B. (2009). "Staff Suggestion Scheme (3Ss) within the UAE Context: Implementation and Critical Success Factors. Education," Business and Society: Contemporary Middle Eastern Issues, 2(2), 153-167.

Ala-Laurinaho, A. $\begin{gathered}\text { (2003). 'Jatkuvaan } \\ \text { Parantamiseen }\end{gathered}$
Kehittyminen Toimintatutkimus Kolmella Sahalla,'. Lisensiaattitutkimus. Teknillinen korkeakoulu, Tuotantotalouden osasto.

Alves, J., Marques, M. J., Saur, I. \& Marques, P. (2007). "Creativity and Innovation through Multidisciplinary and Multisectoral Cooperation," Creativity and Innovation Management, 16(1), 27-34.

Andersen, B., Fagerhaug, T., Randmael, S., Schuldmaier, J. \& Prenninger, J. (1999). "Benchmarking Supply Chain Management: Finding Best Practices," The Journal of Business \& Industrial Marketing, 14(5/6), 378-389.

Anonymous. (2009). 'Continuous Improvement as a Business Strategy,' Management Services, 53(3), 32-35.

Bateman, N. \& Rich, N. (2003). “Companies' Perceptions of Inhibitors and Enablers for Process Improvement Activities," International Journal of Operations \& Production Management, 23(2), 185-199.

Beddows, A. (2001). "Suggestion Schemes for the Future," Management Services, 45(2), 1415 . 
Journal of Organizational Management Studies 8

Bernett, R. \& Nentl, N. (2010). “Opinions and Expectations about Continuous improvement Programs," The Journal for Quality and Participation, 32(4), 35-38.

Boeddrich, H. J. (2004). "Ideas in the Workplace: A New Approach towards Organizing the Fuzzy Front End of the innovation Process," Creativity and Innovation Management, 13(4), 274-285.

Coleman, A. (2007). 'Need Ideas? Ask Your Staff,' Director, 61(1): 27.

Crail, M. (2006). 'Fresh Ideas from the Floor,' Personnel Today, 6(20), 30-31.

Darragh-Jeromos, P. (2005). 'A Suggestion System that Works for You,' SuperVision, 66(7), 18-19.

Doolen, T. L., Van Aken, E. M., Farris, J. A., Worley, J. M. \& Huwe, J. (2008). "Kaizen Events and Organisational Performance: A Field Study," International Journal of Productivity and Performance Management, 57(8), 637 - 658.

Drejer, A. (2002). "Situations For Innovation Management: Towards a Contingency Model," European Journal of Innovation Management, 5(1), 4-17.

Garrison, B. (2009). 'People Power,' Refrigerated \& Frozen Foods, 20(8), 28-33.

Hogan, B. J. (2009). 'Sustaining a Lean Culture,' Manufacturing Engineering, 143(5), 71-76.

Järvinen, P. \& Järvinen, A. (2004). 'Tutkimustyön Metodeista,' Tampere: Opinpaja Oy, 211 s.

Jepson, K. (2010). 'How CU Saved \$250K With Process Improvement,' Credit Union Journal, 14(3), 1.

Larikka, M., Heinilä, P., Selin, K. \& Tuominen, J. (2007). 'Tuottavuuden Jatkuva
Parantaminen,' Teknologiateollisuus ry. Tampere.

Larikka, M. \& Pohjasmäki, J. (1995). 'Jatkuva Parantaminen: 100 käytännön esimerkkiä,' Metalliteollisuuden keskusliitto. Tampere.

Lillrank, P., Shani, A. B. \& Lindberg, P. (2001). "Continuous Improvement: Exploring Alternative Organisational Designs," Total Quality Management, 12 (1), 41-55.

Mini. (2004). 'Human Resources', 8.

Pollit, D. (2010). "Qatar Steel Forges Ahead with Quality Circles: Manufacturer Builds on 30 Years of Continuous Improvement," Human Resource Management International Digest, 18(2), 16-17.

Rad, A. M. M. (2006). "The Impact of Organisational Culture on the Successful Implementation of Total Quality Management," The TQM Magazine, 18(6), 606-625.

Rapp, C. \& Eklund, J. (2002). "Sustainable Development of Improvement Activities The Long-Term Operation of a Suggestion Scheme in a Swedish Company," Total Quality Management, 13(7), 945-969.

Salaheldin, S. I. (2009). "Problems, Success Factors and Benefits of QCs Implementation: A Case of QASCO," TQM Journal, 21(1), 87100.

Salaheldin, S. I. \& Zain, M. (2007). "How Quality Control Circles Enhance Work Safety: A Case Study," The TQM Magazine, 19(3), 229-244.

Singh, J. \& Singh, H. (2009). "Kaizen Philosophy: A Review of Literature," The ICFAI Journal of Operations Management, 8(2), 51-72.

Tonnesen, T. (2005). “Continuous Innovation through Company Wide Employee Participation," The TQM Magazine, 17(2), 195-207. 